\title{
ANASTHESIA IN GENERAL PRACTICE.
}

BY JAMES PATON BOYD, M.B.

THE aim of this contribution is to give some suggestions to practitioners who are not giving anæsthetics regularly. I have often thought in reading the many text-books, large and small, on anæsthesia that for the most part they devote themselves too much to descriptions of complicated apparatus, and not enough to plain indications as to how anæsthetics should be given in the simplest and safest manner. Undoubtedly the ideal method is the open method of administering ether, as the apparatus required is simply a mask allowed to rest on a gauze face-pad, but, unfortunately, in a very considerable number of cases it is difficult, not to say almost impossible, to obtain speedy and efficient anæsthesia. On the whole, the practitioner will find that it is better to start with chloroform, but the administrator must constantly remember that he is dealing with a lethal drug which produces an overdose readily in susceptible subjects.

The apparatus requisite is some form of mask. It is true that in an emergency the corner of a towel drawn through a safety-pin is sufficient, but it readily gets saturated and blisters the face. Schimmelbusch's frame answers the purpose admirably, and the larger and deeper its gutter the less chance of any chloroform dripping over. As regards material with which to cover the mask, surgeon's lint, flannel, or domette is most frequently employed. Personally I prefer "sponge cloth," which retains the chloroform and does not soak through readily. Secondly, you require a chloroform bottle. There are innumerable varieties, but the cheap glass drop bottle obtained in any chemist's is as serviceable as many of the more elaborate devices. Lastly, a gag and tongue forceps are essential.

Now, suppose your patient is in the dorsal position, with head low and nothing constricting the neck or body. You proceed 
as follows:- Hold your mask about an inch from the patient's face. Tell him to blow away the vapour if there is any tendency to choking. Now begin to drop your chloroform, and as soon as the patient gets accustomed to it lower your mask on to the face, and continue to drop continuously till anæsthesia is attained. Levy, in an article on "Cardiac fibrillation and chloroform syncope," states " that in giving chloroform the first principles are to keep the patient fully anosthetised and to make the administration continuous. In the induction stage the administration should not only be continuous but progressive; the strength of the vapour should be increased as rapidly as possible without distressing the patient." I quote this as I believe it to be absolutely true. If an anæsthetist pours on a few drops, then stops, and thus gives it at irregular intervals, the almost constant result is that the patient does not go under, and ends up by becoming faint with cessation of breathing and subsequent sickness. Your aim ought to be to give your chloroform in increasing quantities till the first signs of surgical anæsthesia show themselves. I want briefly to indicate what it is essential to take stock of during anæsthesia.

1. Respiration.

2. Colour and pulse.

3. Eye conditions.

4. Muscular conditions.

1. Respiration.-It is of the utmost importance to watch respiration from start to finish. At first there is a tendency to hold the breath. I have frequently noticed students when giving chloroform (during the early struggling stage, wherein the patient invariably holds his breath) pouring on chloroform on the mask in increasing quantities, whereas the mask ought to be removed till the patient starts breathing again; for if the breath is held for a time you are apt to get very deep inspiratory efforts on the resumption of breathing, and if your mask is soaked with chloroform you are prone, if it is suddenly absorbed into the circulation, to have the patient getting an overdose with sometimes fatal results. As anæsthesia advances you normally find the respiration becoming regular, automatic, and slightly snoring in character. 
2. The colour and pulse, which are the guides to the state of the circulation, must have the administrator's constant attention. When a patient is put on the operating table always note the colour of the face and lips, because you have thus a guide throughout the operation and any change is immediately recognised. It is quite unnecessary to be constantly taking the pulse, but if you feel it to begin with, you can note from time to time any alteration.

3. Eye conditions-Of all signs which give one an idea of the stage of anresthesia reached, the above furnish all important information. You ask the patient before applying the mask to shut the eyes. Not infrequently, quite in the early stage, a certain amount of tremulous movements of upper and lower eyelids is seen. When this passes off, test the lid reflex by pulling on the upper eyelid. At first directly you pull up the eyelid it closes smartly, but as anæsthesia develops the movement becomes fainter, and is ultimately abolished. Now is the time to test the corneal reflex. I have been often struck to observe that many trying to elicit it pull upon upper and lower eyelids and then insert the finger between the margins of the lids, and thus prevent the response of the lids. The right method is gently to brush the pulp of the middle finger over the centre of the cornea, when the contraction of the lids manifests itself.

A word of caution is necessary : do not be constantly testing this reflex, as you are apt to irritate the eye and may set up a conjunctivitis. Moistening the finger with vaseline is advised to decrease the possibility of that occurring. At anyrate, the sign should be brought out by the gentlest possible touch. This reflex becomes fainter as anæsthesia progresses. In many cases it is not essential to abolish it entirely. As the corneal reflex disappears, the movements of the eyeballs become of interest. The eyes squint in various directions, sometimes outwards or inwards, and then tend to come nore towards the middle line, and not infrequently rotate downwards. Finally, the eyeballs come to be fixed in the middle line looking straight forwards.

The pupils at first are dilated, but as the movements of the 
eyeballs cease they tend to contract. At first they respond readily to light, but afterwards become steadily contracted as anæsthesia progresses. In a certain percentage of cases the pupils never contract throughout the operation, and they are always a source of anxiety, though anæsthesia may be quite efficient. When a contracted pupil dilates it is due either to too light anæsthesia or to overdosage. In making up your mind as to which it is, you have to be guided by other conditions. In a case where it is due to too light anæsthesia the respirations tend to get shallow ; squinting or movement of the eyeballs and return of the corneal reflex show it to be so. In cases of overdose, pallor, absence of corneal reflex, and the eye dry and lustreless from inhibited lacrimation show the condition. There is no question, however, that if you have the slightest doubt you should withdraw your anæsthetic at once, even at the risk of vomiting ensuing from too light anæsthesia.

One more eye sign of interest is lacrimation. In the British Medical Journal, 21st June, 1913, L. T. Rutherford called attention to "the lacrymal gland in surgical anæsthesia;" and since then I have been able to corroborate his conclusions, viz., that the appearance of lacrymal secretion at the inner canthus of the eye is a constant phenomenon, and that it has a definite relationship to the depth of anæsthesia. Even after the cornea] reflex is entirely abolished, you find lacrymal secretion collecting, which is an indication that if required you can push your anæsthetic, and when the pupil is dilated it gives one confidence that you are not overdosing.

4. Muscular conditions.-The state of the masseter muscles is most helpful during anæsthesia, because you should invariably have control of the lower jaw with your left fingers. You find that till your patient is pretty deeply under, there is more or less pulling of the jaw against your fingers, due to spasm and rigidity which disappear as anæsthesia ensues. In abdominal operations especially, where abdominal relaxation is essential, this sign is most useful to the anæsthetist.

I have, in discussing the various conditions which have to be taken account of in anæsthesia, gone over much that is already familiar to readers of this article. I wish, however, to emphasise 
that it is only by a due recognition of these points that we are able to obtain safe and efficient anæsthesia. No method of percentage administration, in my opinion, will ever produce perfect safety. We ought to graduate our dosage entirely by watching the various symptoms produced by chloroform, as we can never tell beforehand how any individual will behave under its influence. In text-books you have laid down hard and fast statements as to how various ty pes of patients take anæsthetics. To a certain extent they may be true, but clinically you find that it is not till you have the patient under the influence of the anæsthetic for some time that you can gauge definitely the effects of the drug.

In conclusion, I wish to suggest to practitioners what I consider would promote safer anæsthesia once you have by chloroform inhalation put your patient into a state approaching what is termed surgical anæsthesia. By that I mean that the respiration is audible and regular, the corneal reflex nearly abolished, and the eyeballs fixed in the middle line with contracted pupils. You should then change to open ether. As regards an ether bottle, nothing is better than an ordinary 8-oz. dispensing bottle, into which is fitted an Allen und Hanburys double-tubed stopper. It is cheap and fits almost any bottle. You can commence dropping your ether on your chloroform mask, but I think it better to have another mask which is covered with two layers of surgeon's lint. You commence dropping your ether freely, thoroughly saturating your mask. Remember it is hardly possible to give an overdose with ether. If you find that the patient is tending to come out of the anæsthetic you can produce a stronger vapour by covering the nask entirely with a small folded towel some four-ply thick. You can make a small opening at the apex of the mask to pour your ether in, or covering completely turn up your mask and pour into its interior a drachm or so of the anæsthetic, and reapply from time to time. If in spite of this you find the anæsthesia getting too light, return to your chloroform mask and give chloroform till you again get the patient more deeply under. Then back again to your ether. You thus give ether as long as the patient keeps under satisfactorily, and you have 
chloroform in reserve if a deeper anæsthesia is desired. You will find this method of particular benefit where under chloroform your patient tends to become faint, as shown by pallor and feeble respiratory efforts. Undoubtedly, by pushing your chloroform in the majority of cases the faintness passes off, but you are apt to be obsessed with the thought that the patient is getting an overdose. The giving of ether is then perfectly safe, as it gives respiration the needed stimulus through its effect on the heart.

I have said nothing about giving chloroform and ether combined in various proportions, because it has always seemed to me far better to use them separately, so that you can, as I have indicated, give one or other as the circumstances demand. 